\title{
An Investigation of the Translational Asset: A Proposed Classification
}

\author{
Gennaro Strazzullo ${ }^{1}$ William J. Ion ${ }^{1} \cdot$ Jillian MacBryde ${ }^{1}$
}

Received: 9 September 2020 / Accepted: 7 June 2021 / Published online: 5 November 2021

(c) Crown 2021

\begin{abstract}
Translational assets (TAs) are considered one of the actors that play a critical role within the national innovation system (NIS) of every country that embraces university, government, and industry collaboration. Moreover, these organisations have been established to support industries, companies, and particularly SMEs, filling the university-industry gap. Although the establishment of translational assets creates many benefits, this organisational ecosystem has been a controversial topic. It is hampered by a lack of consensus on how to define and classify translational assets. The problem arises because of their heterogeneity. This study identifies the critical factors for presenting a general classification from the analysis of academic papers and technical reports. The proposed classification is built, showing the factors of organisational structure, resources, and motivation for collaboration on a bidirectional continuum. Therefore, this paper's findings provide a proposed classification of three main types of TAs, which are as follows: exploratory, plug, and developer/ solver. This is a heuristic classification that provides enrichment to the literature and a better understanding for practitioners of these organisations' behaviour.
\end{abstract}

Keywords Translational asset $\cdot$ Applied research $\cdot$ Classification $\cdot$ Theoretical typology

This article is part of the Topical Collection on University and Entrepreneurial Ecosystems

Gennaro Strazzullo

gennaro.strazzullo@starth.a.c.uk

William J. Ion

w.j.ion@stath.ac.uk

Jillian MacBryde

illian.macbryde@strath.ac.uk

1 Department of Design Manufacturing Engineering \& Management, University of Strathclyde, Glasgow, UK 


\section{Introduction}

In a knowledge economy, there is a consensus that innovation represents, for almost all organisations, one of the keys for surviving and increasing competitiveness and knowledge is the driver for it.

Therefore, companies started to look beyond their boundaries and engage with other organisations to absorb knowledge as input to satisfy their scarce resources or capabilities, know-how, and reduce the risk of new product/service development. This strategical approach is known as open innovation, and opening their R\&D boundaries for collaboration is the core of this paradigm (Arrigo, 2018; Chesbrough et al., 2006; Subtil de Oliveira et al., 2019). There are different levels of "openness" based on the firms' operating environment and the organisations with which the industries established new collaborations such as universities, intermediate institutions, and government bodies.

Despite the different perspective between university and industry, they often work in partnership. As enterprises have begun to establish new collaborations with several stakeholders, universities shifted their logic taking on entrepreneurial tasks (Leydesdorff \& Etzkowitz, 1995) through the translation of knowledge (Etzkowitz et al., 2019). Universities, industries, and government are the main institutional R\&D components in the knowledge economy model defined by Leydesdorff and Etzkowitz, known as Triple Helix. These national infrastructures that facilitate $R \& D$ and its contribution to technological innovation work on the macro- and micro-level. The macro-level is made from university, industry, and government, aiming to provide research activities. The micro-level consists of business that transforms service/product that embody the new technologies, which brings to an economic value (Betz et al., 2016; Sarpong et al., 2017).

The intersection between the helixes is the key to innovation. Indeed, the collaboration between university-industry has been encouraged by governments and funding agencies in developed and developing countries. The different supports provided by the government for innovation comprise research, technology and innovation policies, and other policy measures such as financial instruments (i.e. R\&D innovation grants, tax incentives with a focus on collaboration) and regulatory mechanisms (i.e. (IP) right regime, incentives to different parties involved in the university-industry cooperation), and many else (Morrison \& Pattinson, 2020; OECD, 2019). One of the policy strategies supporting research and sustaining the relationship between university and industry is establishing bridging organisations that facilitate the linkage between two entities. These organisations operate in the middle level of the technology readiness level (TRL) to resolve the translation gap. TRL is a 9-level scale used to assess innovation project eligibility based on their maturity (Figs. 1 and 2).

The translational problem is very prominent in the pharmaceutical industry but is found in other sectors such as manufacturing (Haeussler \& Assmus, 2021). The term "translation" is meant the process of transforming basic research knowledge into use in the real-world promoting innovation of both products and process (Garegano, 2019). 
Fig. 1 Technology readiness level (EARTO, 2014)

\begin{tabular}{|c|c|}
\hline TRL Scale & Description \\
\hline TRL 1 & Basic principles observed \\
\hline TRL 2 & Technology concept formulated \\
\hline TRL 3 & Experimental proof of concept \\
\hline TRL 4 & Technological validity in a lab \\
\hline TRL 5 & $\begin{array}{l}\text { Technology validated in relevant } \\
\text { environment }\end{array}$ \\
\hline TRL 6 & $\begin{array}{l}\text { Technology demonstrated in relevant } \\
\text { environment }\end{array}$ \\
\hline TRL 7 & $\begin{array}{l}\text { System prototype demonstration in } \\
\text { an operational environment. }\end{array}$ \\
\hline TRL 8 & System completed and qualified \\
\hline TRL 9 & $\begin{array}{l}\text { Actual system proven in operational } \\
\text { environment }\end{array}$ \\
\hline
\end{tabular}

The model of this type of organisation has been widely diffused during the last four decades, initially in western and more developed countries such as the USA, Australia, and Canada, and then has been set up in Europe in Italy, the UK, Netherland, Germany, Finland, France, Spain, and others. Thus, these bodies occupy a unique place within the innovation ecosystem by playing a crucial role in the country's economic growth through the creation, employment, and diffusion of knowledge (OECD, 2011a, b). The role played by these entities fits the state of the innovation system of the nation as they change based upon their strategies, structures, and economic orientation (Arnold et al., 1998). However, their worldwide presence brings some confusion proving their definition and classification (Ciappetti \& Perulli, 2018). However, we are aware that not a publication has addressed this terminology inconsistency yet. These organisations have been labelled using several terms over time (Youtie et al., 2006) in the policy arena such as translational

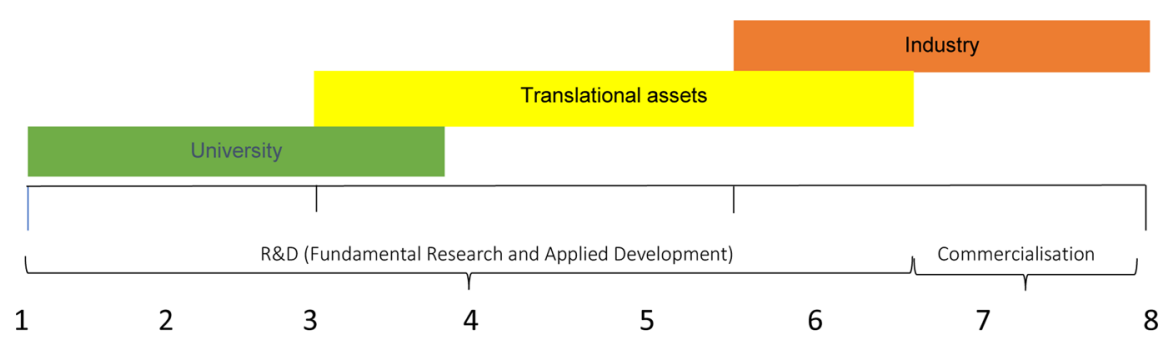

Fig. 2 Technology readiness level (TRL) (own elaboration) 
infrastructures (Hauser, 2010), R\&D laboratories (Crow \& Bozeman, 1987a, b), research centre (Boardman \& Corley, 2008), or research institute (Stahler \& Tash, 1994). To simplify this issue, in this paper, these institutions will be labelled under the umbrella term of "translational asset (TA)," used first by Hauser (2010) in his report where he highlighted the need for the UK to fill the gap between industry and university.

With the term asset, we want to include tangible (i.e. equipment) and intangible (people) resources. Commonly, the term asset identifies only the tangible resources, then to only the infrastructure. However, we adopt the new term of translational asset for two reasons: the first is because it is becoming popular in the UK in both the academic and practitioner environment, and second, which is the more important reason, the organisations, especially those involved in $\mathrm{R} \& \mathrm{D}$, are recognising the value of the talent, skills, and knowledge as drivers for a successful organisation. Therefore, in this analysis, it is essential to link the concept of asset to tangible and intangible resources to have a clear idea of what the TAs are. Moreover, the concept of assets can be linked to that of infrastructure. Therefore, we have used these two terms interchangeably.

Ultimately, the need for classification is manifold. This research particularly wants to assess the different primary factors that distinguish the different R\&D organisations' boundaries. To achieve this objective, the investigators conducted a qualitative study based on the triple-helix theory and the general literature at the international level about the TAs. This research is the starting point for studying this broad field of organisational theory and R\&D and innovation management. Its contribution has impacts on theory and practice. The proposed general classification aims to fill the literature gap by clarifying the different types of TAs from a holistic perspective. This initial piece of research could enrich the theory through a framework and provide suggestions to practitioners in this field to examine and improve their organisations and policymakers needing a better understanding of the nature of the typologies of these organisations.

The paper is structured as follows: first, the authors introduce how the universities and the research organisations are changing their role within their ecosystem; the second section presents the existing classifications used in the literature of the different research organisations; the third section shows the typology and the variable considered to build it up; in the end, in the fourth section presents the conclusion and discussion in which includes further studies.

\section{Approach to the Study}

For this investigation, our main objective is to establish the diverse factors that define the translational assets to identify the main typologies that operate within a national innovation system (NIS). This objective was influenced by the relatively novelty of this issue and from the fact that such a phenomenon is still a grey concept from practitioners and academics. From here, the challenge is to categorise the TAs according to the existing literature. 
The authors aimed to analyse this phenomenon and to so they address the research question, "what does the literature says about the main factors that have been used to characterise the TAs?" The question has been answered by reviewing the literature on the characteristics of a variety of translational assets.

The purpose of the literature review was to have a background of information in the field and understand the main characteristics to classify these organisations according to the most influential scholars. The sources analysed distinguish various translational infrastructures with different reasons to be established for public and private support. The authors think that the difficulty in exploring this field does not come from the limited data but from the blurry concepts that shape this topic's boundaries, especially regarding the translational assets covering the mid and high TRL.

To gather information for the literature review has been used an electronic database (Science Direct) considering publication from the past three decades and considering different reports issued by governmental bodies and other translational assets within various OECD (Organization for Economic Cooperation and Development) countries and in the USA involved in science, technology, and engineering domains. Within the database, we searched using the combination of key terms as "research university" OR "research and technology" OR "research centre" OR laboratories AND "organisation design" AND classification OR typology. Research Policy, Technovation, and Technology Forecasting and Social Change as the principal journals in research and innovation were considered to identify the relevant articles. The papers considered have mainly empirical findings gained from case studies. The authors read the first set of papers, and a snowball approach has been applied to gather further documents. Therefore, the literature analysis was useful to distinguish these organisations at a high level to classify and naming them according to relevant factors.

There is a call to a few a priori studies (notable Bozeman \& Crow, 1990; Bozeman \& Moulton, 2011; Crow \& Bozeman, 1987a, b; Sanz-Menéndez \& Cruz-Castro, 2003; McNie et al., 2016) about how these types of R\&D organisations have been classified based on different dimensions. Nevertheless, as a result, these studies seem to be insufficient for recognising TA types failing to present a general classification scheme as they lack heterogeneity and sharp demarcations (McKelvey, 1982). Moreover, these past studies did not use an extensive list of factors to identify different types. For this reason, with the existing classifications, some organisation could not be collocated within the right group. This issue has been addressed in this paper by considering key factors and representing them on a continuum. The representation on a continuum eases the inclusion of hybrid organisations and better segmentation of the TA types. Only the necessary information has been collected from the literature sources to fill the variables that build the theoretical framework. In the following section, the analysis of the sources of literature on the translational assets and their past classifications. 


\section{Theoretical Background}

\section{Changing of Roles}

In a context where the production of knowledge and its diffusion drives the growth of every national economy, research and development, in all its forms, and innovation induce changes of organisational and institutional nature. These changes caused by $R \& D$ costs, concurrency, or the risk of launching new technologies have seen the industries to require the support of the implementation of research and innovation initiatives within the industry boundaries to boost their growth. These initiatives do not bring only industrial development but also impact a social point of view.

In this wave of change, the knowledge-based economy context brought about a substantial revolution in the research landscape (Bazan, 2019). Mainly, the university has made a significant change: it shifted from its traditional academic activities of teaching and research activities to a third one. This third mission sees the university cover a substantial role in innovation, for example, by the commercialisation of the research outputs through the transfer of knowledge and the change of its funding sources. This transition brought about the birth of a university's new model: a university of entrepreneurial nature (Muizniece, 2020). In this way, the old linear model of innovation (from basic research to commercialisation) has been replaced as the industries try to resolve their challenges through science.

Another aspect due to these changes is about the freedom acquired from the investigators and how they started to set their research agenda with activities beyond the fundamental science's scope. By showing its innovation outputs, the university eases its connection with potential investors. The industry also found the university a valuable partner for its R\&D objectives by having access to tangible and intangible resources (Bazan, 2019). These developments are described in the Triple Helix model, which represents the synergy between university, industry, and government that drives innovation and economic growth (Etzkowitz, 2000).

Moreover, a further change has been the need for a multidisciplinary approach to overcome industrial challenges. An example of this change can be seen in the translational asset that gathers researchers with different expertise to address complex problems in a specific context to create and transfer knowledge to the stakeholders involved in the collaboration.

These types of entities can be identified at the meso-level of the Triple Helix model, and according to Etzkowitz and Leydesdorff (2000), there are three different types of institutions:

- Hybrid innovation agents (responsible for the production and use of knowledge);

- Innovation interfaces between firms and public research;

- Hybrid innovation coordinators that provide coordination between the traditional research actors.

The concept of hybrid organisations covers various meanings based on the context in which the organisations fit. For this investigation, an intermediary 
organisation is conceived as an organisation (that carry out research activities) with a sequence of different characteristics and operating models (De Waele et al., 2015) based on their remit, stakeholders, organisational structure, and funding stream. Despite their relevance, the evolution of the translational asset has not had the same attention as the universities' transformation (Cruz-Castro et al., 2015). We may attribute this lack of consideration towards the translational assets because of the low expenditure in R\&D by governments. Scholars could also give more attention to the university because of the shift of the fundamental research beyond what were its boundaries through a multidisciplinary approach, new research activities, and their higher impact.

Nevertheless, introducing this new actor within the innovation ecosystem brought to the development of new collaborations. For instance, the partnership between university, industry, and the translational asset is strongly encouraged by the governments of each country, and it has brought both technologies and services to the firms, especially to the small and medium enterprises (SMEs) (Adams et al., 2001; D'Este \& Patel, 2007). There are several mechanisms to establish a university-industry collaboration, both formal and informal such as collaborative research, research contracts, consulting, spin-off, IP transfer, licensing (D'Este \& Perkmann, 2011; Etzkowitz et al., 2019), creation of physical facilities, postgraduate training in the company, training company employees, and joint research agreements (D'Este \& Patel, 2007).

Therefore, these changes have entirely turned the R\&D landscape and emphasised the role of these meso-level organisations. Since our principal objective is to classify these organisations, the following section reviews the effort made by the previous scholars to develop a classification of the TAs.

\section{Typologies of Translational Assets in Literature}

\section{General Definition of Translational Assets}

Although these organisations are not a new phenomenon in the innovation landscape, there is still a limited understanding of this complex type of organisations. An argument could be the hybrid nature of the organisations. Therefore, it is appropriate to attempt to analyse the variety of innovation organisations encompassing those most frequently known in literature and practice such as the research centre, research institutes, government laboratories, technology centres, and research and technology organisations (Cruz-Castro et al., 2020).

One of the causes of the lack of understanding is the birth of new types of innovation organisations to which have been associated with a variety of definitions that have created confusions between the scholars (Gray et al., 2013). Over the years and in every NIS, the definition of "translational asset" has evolved. Several definitions have been attempted, trying to expand the concept of innovation organisation from what was initially conceived as a traditional academic department. Table 1 proposes a selection of several definitions of the translational asset from literature sources and reports from different countries. 
Table 1 Selection of definition of innovation organisations

\begin{tabular}{ll}
\hline Sources & Definitions \\
\hline Gray et al. (2013) & A Cooperative Research Center (CRC) is an organisation or unit within \\
& a larger organisation that performs research and also has an explicit \\
mission (and related activities) to promote, directly or indirectly, & cross-sector collaboration, knowledge and technology transfer, and \\
& ultimately innovation \\
& ICs (Innovation Center) are defined as organisations focused on the \\
& exploitation of new technologies, through an infrastructure which \\
& bridges the spectrum of activities between research and technology \\
Hauser (2010) & commercialisation \\
& IUCRCs (Industry-University Research Center) [...] are designed \\
& to foster technology transfer between universities and firms. Since \\
IUCRCs are small academic centres that depend mostly on industry \\
support, we expect them to advance the research of member compa- \\
nies
\end{tabular}

Bozeman and Boardman (2003) Academic departments are discipline-based units charged with teaching, research, and service missions

Bozeman and Boardman (2003) URC as a formal organisational entity within a university that exists chiefly to serve a research mission is set apart from the departmental organisation and includes researchers from more than one department (or line management unit)

BIS (2015)

$\operatorname{OECD}(2011 \mathrm{a}, \mathrm{b})$

RIOs in the UK are defined as non-profit organisations that perform research and innovation support as their main activity, whose existence depends on a significant degree of public funding, and whose work serves some public policy purpose

PRO is used to refer to a heterogeneous group of research performing centres and institutes with varying degrees of "publicness". [..]can distinguish four ideal types: mission-oriented centres, public research centres and council (PRCs), Research and Technology Organization (RTOs), Independent Research Institutes (IRIs)

Ikenberry and Friedman (1972) Fully funded by Government and the funds were provided only for specific purposes. The main reason (frequently cited) for the creation of institute is the increased demand for multidisciplinary or interdisciplinary collaboration

House of Commons (2011) Research and Technology Organisations (RTOs) is the term given to specialised knowledge organisations dedicated to the development and transfer of science and technology to the benefit of the economy and society. RTOs [...] operate on both a commercial and not-forprofit basis with a focus on more routine and commercially lucrative laboratory and technical consultancy services

While various definitions of the term "translational asset" have been suggested, this paper will use the definition first proposed by Hauser (2010). We opted to choose Hauser's description because the other definitions in the table highlighted translational assets' characteristics like university-based, public-funded or industrydriven. In contrast, Hauser has a broader perspective as he sees TAs as organisations that collaborate with both private and public entities to adding value to the R\&D process through the employment of technologies to attempt to fill the gap of the Valley of Death, that is, the gap between the research economy and the commercial 
economy (Jucevicius et al., 2016). Therefore, this definition is closer to our idea of a translational asset.

Other than struggling to find a clear-cut definition, there is a problem identifying a classification for the TAs. It is then appropriate to understand what distinguishes these entities by identifying several dimensions. This drives to build a framework that proposes a classification of how these organisations can be described.

\section{Theoretical Typologies}

This state-of-the-art classification is mainly due to the lack of conceptual clarity and conformity of the terminology adopted (Cruz-Castro et al., 2020). The different types of R\&D based on the users have brought to the establishment of a varying kind of translational assets. The word classification has a different meaning in literature and often has been identified as typology or taxonomy. According to many authors (see Carper \& Snizek, 1980; Hambrick, 1983), there is not a substantial difference between the two terms. Rich (1992) affirmed that a typology classifies data into types based on a priori theory.

In contrast, the taxonomy is a classification scheme aiming to represent empirical data in similar groups in a hierarchical fashion. In this analysis, the classification is identified with the term typology. According to Collier et al. (2008), typologies are understood as "organised system of types" and "is useful only if it reduces the redundancy and complexity of many variables" and "to reduce the redundancy and the complexity of the competing typologies" (Kilmann, 1983). The introduced typologies have been built considering data from deductive theories present in the literature. Moreover, being a theoretical typology, this investigation represents only the first step toward a system of classification and not the final one (Carper \& Snizek, 1980). Its scope is to provide a framework for describing the nature of the different innovation organisations.

\section{Typologies A Priori}

We have stated above that the field of translation assets is a "grey" topic in literature. Thus, there are not many classifications of such organisations, and those existing do not present any homogeneity. Most of the literature aims to classify the industry-university cooperative research centre (Boardman \& Gray, 2010). Thus, there is a lack of knowledge regarding other forms of R\&D organisations. Mainly, the past classifications involve the changing environment due to the influence of the government and market (Crow \& Bozeman, 1987a, b), stakeholders (Hagedoorn et al., 2000; Adams et al., 2001), type of technology transfer (Hameri, 1996), type of research (Geiger, 1990).

The main factors that several authors have considered will be analysed to design the existing classifications.

Environment: R\&D organisations face various environments that impact the organisation overall (Aldrich \& Herker, 1977). Crow and Bozeman (1987a, b) have investigated the context of the American $R \& D$ laboratories considering their legal status or ownership (public, private, or non-profit). AIRTO (2018) has provided a 
clear definition of the different legal status in one of its report. This variable shows the logic that prevails in the organisational environment. Several variables affect the organisational environment but what we think is the most appropriate variables to describe it are the "publicness" that identifies the degree of government influence on the organisation and the market influence. Indeed, laboratories can be owned by a public or private organisation like government and university or industry. Simultaneously, the products can be identified as generic products with low market influence, balanced products with a moderate influence and property products having a heavy market influence (Crow \& Bozeman, 1987a, b).

Collaboration: The collaboration between university, industry, and government has strategic importance and brings advantages to all the parties involved. Several scholars such as Feller et al. (2002) have investigated the perspective of the university on innovation organisation to emphasise the new face of the university as an entrepreneur (Etzkowitz et al., 2019), while other studies considered the collaboration between the innovation organisation and industry partner (Boardman \& Corley, 2008). Collaboration goals are critical for the success of a partnership because they are related to the structure of collaboration. These goals target knowledge generation, basic research, sharing of resources, interaction with the community, and career development. This collaboration can start through a bottom-up process, top-down process, or mixed process (Corley et al., 2006). Hagedoorn et al. (2000) and Bonaccorsi and Piccalunga (1994) classified the motivations that drive members within the ecosystem to engage in this collaboration. The private sector involves this collaboration for several reasons such as having access to resources like highly qualified personnel and valuable knowledge (Bonaccorsi \& Piccalunga, 1994); exploiting their resources and developing sustained competitive advantages; increasing the efficiency, synergy, and power through the networks; learning to build up new skills and capabilities; and internalising core competencies and enhancing competitiveness (Hagedoorn et al., 2000). Moreover, policymakers encouraged university-industry partnerships to correct market failure, accelerate technological innovation, and increase technological innovation exchange among firms, universities, and public research institutes (Cohen \& Levinthal, 1989; Hagedoorn et al., 2000).

Organisational Structure: The structure is one of the key variables used to classify organisations. Among the organisational structure advocates, Burns and Stalker (1961) describe the organisation's structure as either mechanistic or organic, considering the hierarchy levels. Their classification is questionable because it could be obsolete or inconsistent, even if many scholars still use Burn and Stalker's classification to analyse the organisational structures. Nowadays, many R\&D organisations attempt to increase their flexibility level independently of their size and hierarchical levels. Other factors that influence the structures are the research projects' scale and research autonomy (Jordan, 2006). Instead, it would be more relevant if scholars would analyse an organisational structure under collaboration format lenses. The study of Champalov et al. (2002) and Bonaccorsi and Piccalunga (1994) on the typology of organisation and management of the partnership by considering the different dimensions of bureaucratisation (leadership, formalisation, hierarchy, and division labour) is a notable example. 
Resources: Generally, for the translational assets, the primary organisational variables considered for classification are the financial model, the human capital, and research infrastructures (equipment). Those variables can be seen as input for an R\&D organisation. The last two elements can represent a set of capabilities for the TAs. Funding is one of the critical factors that distinguish the different form of organisations because it has a remarkable influence on the research's orientation and how organisations set priorities (Etzkowitz \& Kemelgor, 1998; Lal et al., 2007). The funding is available from the R\&D programs, government, and industries (Balthasar et al., 2000) to support new ideas and the initial demonstration that they work (Auerswald \& Branscomb, 2003; Youtie et al., 2006).

Moreover, the funders outline the geographical scale of the organisation's operations. The organisations established and funded by the regional government limit their activities to their home region. At the same time, those who receive national government funds address national needs (e.g. Fraunhofer Institutes) (Charles \& Ciampi, 2014). The sources and the amount of funding received from translational assets show where they fit within the technology readiness level spectrum. However, they do not drive the research agenda of the TAs. If an organisation receives a majority of funding from a single stakeholder, the management and the researchers pursue their research objectives without neglecting the stakeholder interests (Lal et al., 2007). This could be partially true as, for instance, for a TAs that has industrial members that bring a considerable percentage of funding to the organisation force the research to satisfy the member's needs firstly.

In contrast, if the funding stream comes from different players, the organisation may cover different directions (Gulbransden 2011; Crow \& Bozeman, 1987a, b). Therefore, various sources allocate funding to the TAs. Thus, the management of a TAs have to establish a clear mission and vision to avoid inefficiency and loss of funding in the future.

Human capital is an essential component in the TAs and consists mainly of scientists, researchers, technicians, and researcher students (Adams et al., 2001). This resource presents a certain autonomy level based upon funding and management (Jordan, 2006). It can be diversified based upon the size and the functions of the personnel. Jordan (2006) classifies individuals and a group's competencies, considering the specialisation level with specific expertise and the complexity and diversity of the research teams. Lal et al. (2007) classified the personnel as academic faculty, research faculty, and research staff. Research infrastructures are also relevant, but not all innovation organisations have the same equipment and space. For instance, ample laboratory space, workshop and up-to-date instrumentation, and other resources are not available for innovation organisation based within the university. Therefore, not all TAs can have stability in tasks and resources (Ikenberrry \& Friedman, 1972). The TA facilities' capability depends mainly on the level of support they receive (Stahler \& Tash, 1994). Another variable of input linked to the funding stream is the research projects. The projects are classified based upon their "size" and technical and organisational complexity (Corley et al., 2006). The innovation organisations attempt to develop a long-term alliance to have sustained support from their stakeholders (Gray et al., 1986). 
Stakeholders: Stakeholder is a recurring factor in many classifications because the type of stakeholder is linked to the organisation's themes (e.g. Health, digital economy, energy) and because there are different groups based on the kind of innovation organisation and its objectives. For instance, Hagedoorn et al. (2000) classified the stakeholders into public and private. The public stakeholders embrace university and public research centres, while the firms represent private stakeholders. Bonaccorsi and Piccalunga (1994) share the same perspective, considering only the university and the industries. Differently, Adams et al. (2001), Gray (2000), and Leydesdorff and Etzkowitz (1995) stated that the stakeholders for the innovation organisation are represented from the Triple Helix's actors, that is, the university, government, and industry. Gray et al. (2001) and Adams et al. (2001) affirm that the industries support the research programs run from the innovation organisation through membership and usually contribute with more funds (Lal et al., 2007). The spheres represented by the stakeholders influence the culture of the organisations (Gulbrandsen, 2011).

\section{Building a Proposed Classification of TAs}

In this work, the investigators attempt to classify the translational assets through a systemic approach. That is, the translational assets are a complex system, then "it is analysed as a whole entity to describe and understand differences and their origins, to explain the relationship with the surrounding environment, and to arrange types of phenomena into a meaningful order" (McKelvery, 1982). Previous authors suggested different factors for the classifications of organizations (see Table 2). However, these fail as they do not present an approach to a general classification scheme

Table 2 Classification based on the literature

\begin{tabular}{|c|c|c|}
\hline Sources & Classifications & Characteristics \\
\hline Crow and Bozeman $(1987 \mathrm{a}, \mathrm{b})$ & Environment & $\begin{array}{l}\text { - Legal status or ownership } \\
\text { - Government influence } \\
\text { - Market influence }\end{array}$ \\
\hline $\begin{array}{l}\text { Hagedoorn et al. (2000); Corley et al. } \\
\text { (2006) }\end{array}$ & Collaboration & $\begin{array}{l}\text { - Motivation for collaboration } \\
\text { - Organisational structure } \\
\text { - Bottom-up/Top-down process/mixed } \\
\text { model }\end{array}$ \\
\hline $\begin{array}{l}\text { Chompalov et al. (2002); Bonaccorsi } \\
\text { and Piccalunga (1994) }\end{array}$ & $\begin{array}{l}\text { Organisational } \\
\text { Structure }\end{array}$ & $\begin{array}{l}\text { - Bureaucratisation } \\
\text { - Size } \\
\text { - Research autonomy } \\
\text { - Scale of project }\end{array}$ \\
\hline $\begin{array}{l}\text { Gray (2000); Jordan (2006); Stahler } \\
\text { and Tash (1994); Corley et al. } \\
\text { (2006); Lal et al. (2007); Balthasar } \\
\text { et al. (2000) }\end{array}$ & Input & $\begin{array}{l}\text { - Funding schemes } \\
\text { - Human capital } \\
\text { - Research infrastructures } \\
\text { - Research project }\end{array}$ \\
\hline $\begin{array}{l}\text { Hagedoorn et al. (2000); Bonaccorsi } \\
\text { and Piccalunga (1994) }\end{array}$ & Stakeholders & Public, private, and public/private \\
\hline
\end{tabular}


for knowledge economy impact in this organisational context. This issue happens for different reasons. For instance, Burnes and Stalker (1961) analyzed the organizational structure, either mechanistic or organic. These are two arbitrary groups that cannot represent those organizations that fell between the two extremes of a dimension. This discrete way to classify the organizations brings to a lack of stability of the classification because organizations can change over the years because of the instability of their environment due, for example, to the change of stakeholders, globalization, technological convergence, market focus and policy (Arnold et al., 2010). After all, they may be misclassified or left out (McKelvey, 1982). Therefore, it is relevant to identify the organizations that are "mixed" in characteristics considering characteristics. A classification has been proposed to address this issue. The classification is built considering, according to the investigators, the more relevant factors listed in Table 2 that can be relevant for the design and evolution of a TA and can capture the role played within its innovation. These factors involve attributes that authors did not represent through a bidirectional continuum in the previous studies.

Identifying an organisation using a continuum is a useful tool to grasp such phenomena, especially if the organisations operate in a "landscape of tension" as the TAs, which it referees to the need of this organisation to change and be able to create change within their boundaries (Gustafsson \& Lidskog, 2018). Therefore, the dimensions selected to build the classification of TAs are the organisational structure, the resources, and the collaboration (Table 3). Table 3 shows in the left column the factors considered for the classification, in the central column the attributes associated with each factor, and in the right column describes the variable considered for each attribute, following the description of the factors with the related characteristics that will help to identify the different types of R\&D organisations.

\section{Organisational Structure}

The organisational structure is an essential factor for designing an organisation because it is necessary to choose the appropriate configuration to achieve their goals and be high-performance in their environment. Its importance is that it describes the hierarchical lines of authority, information flow between the different levels, responsibilities, and duties (Pugh, 1990). Two dimensions to illustrate this factor

Table 3 Theoretical typology of innovation organisations (own representation)

\begin{tabular}{|c|c|c|c|}
\hline Factors & Attribute & & Spectra of dimensions criteria \\
\hline \multirow{2}{*}{$\begin{array}{l}\text { Organisational } \\
\text { Structure }\end{array}$} & Internal Authority & Low & $\longrightarrow$ \\
\hline & External Autonomy & Low & High \\
\hline \multirow{2}{*}{ Resources } & Funding & Low. & High \\
\hline & $\begin{array}{c}\text { Dedicated Human } \\
\text { Capital } \\
\end{array}$ & Low & High \\
\hline & Infrastructure scale & Low & High \\
\hline \multirow{2}{*}{ Collaboration } & Proximity to the market & Low & High \\
\hline & SMEs Support & Low & High \\
\hline
\end{tabular}


are identified: external autonomy and internal authority of a TA (Cruz-Castro \& Menédez, 2018; Boardman, 2012). These characteristics emphasises the hybridity of the TAs since they have to engage in strategies to account the different expectations of the stakeholders involved (Gustafsson \& Lidskog, 2018).

Considering the autonomy of a TA, this can vary in a range between semi-autonomous and autonomous. The former type is based at the lower extreme of the continuum. It identifies the R\&D organisations part of the university organisational structure (e.g. industryuniversity research centre or organised research unit (ORU)) (Gray et al., 2001) that are more dependent on the state and lack of own budget, infrastructure, and employment (Arnold et al., 2012; Sanz-Menéndez et al., 2011). While at the other end of the spectrum are the organisation with a solid structure, strategy, facilities, and stable relationship between the individuals and stakeholders (Gray \& Rivers, 2013).

Instead, the variable authority depends on the nature of the organisation's management model (Corley et al., 2006) and from the changes in the system funding (Cruz-Castro \& Sanz-Menéndez, 2018). Such a variable aims to measure individuals' autonomy in the decision-making process to pursue their research agenda or curiosity. Corley et al. (2006), in their study about multi-institutional collaboration, identify two levels of authority and autonomy through the bottom-up and top-down approaches. The former describes an informal approach in which the principal investigators have significant freedom to pursue and shape their research agendas (Philbin, 2011) and translating their research to address technical problems and market needs (O'Kane et al., 2020). On the other hand, the second approach where the decisions about the research priorities are taken from the director(s) and filtered down to the working unit (Cruz-Castro et al., 2012). This variety of decision-making approach implies that the innovation organisations can be structured either with a flexible management (decentralised) style or a more formal style (centralised). However, some innovation organisations are structured through intermediate authority mechanisms like the director's strong leadership within the TAs, committee, and advisory board. An example of the mid authority organisations can be identified from a government innovation organisation led by a director appointed by the president of the organisation. Although it is a formal structure, the director has a degree of autonomy to set up the research agenda (Cruz-Castro et al., 2011).

\section{Resources}

TAs need different resources to run their operations. In particular, among the main assets, there are financial resources and human capital and infrastructures. Moreover, the type of resources shows the kind of output of the TAs. For instance, the TAs that are very close to the university could focus on publishing in a scientific journal or carry out more fundamental research. Vice versa, the TAs more industry-oriented are more willing to provide activities as consulting, knowledge and technology transfer, and commercialisation. Innovation organisations are very different between them by design, and the mode of how they are funded is an explanatory factor to see their difference. Financial resources are critical factors because, for example, nonprofit TAs cannot produce internal income, and they cannot be used to buy other 
types of resources (Hoppmann, 2021). The usual sources of funding in TAs are as follows:

- Public Non-competitive Funding: They are long-term government "core" funds which are employed to support the capability building.

- Public and Private Competitive: The organisations have access to this funding through competitive bid or grant from public or private agencies. This funding can be national or European.

- Private or Market Funding: This represents an income from industry through research contracts, annual membership fee, and services with the aim to the dissemination of knowledge for a specific scope.

These funding sources are distributed in different percentages in the organisation based on the organisational strategy. Moreover, this variable impacts the nature of the ownership's organisation. Illustrating this factor on a spectrum, the TAs focused on a faculty member's or department's R\&D interest are shown at the low end. These types of organisations have a high level of institutional core funding. Moving towards the top end of the spectrum, the R\&D organisations have a lower level of core funding and receive external funding from industries and other authorities. Government is the primary funder for the public sector research to guarantee public outputs from the R\&D activities. These types of TAs are mission-oriented (CruzCastro et al., 2011). By using these funds, the TAs can move "a little ahead of market needs." However, in many countries, government funding is decreasing, and this issue drives the TAs to pursue new financing sources by establishing new strategic collaboration with industries. However, to engage with new stakeholder, the organisations have to offer broader capabilities (Arnold et al., 1998). The other funding source is the private sector through collaborative research contracts, patents, licensing, and consultant. The TAs needs to have industry as a stakeholder as these collaboration programmes sustain funds (Bozeman \& Boardman, 2003).

Human capital is one of the pillars for the R\&D organisations as they rely on researchers and technicians' different expertise in different areas. This resource varies based on the type of organisation. According to Tijssen (2018), skilled human capital is a fundamental to entrepreneurial success because of the ability to recognise future opportunities and exploitation and commercialisation of their research. Scientists and researchers need to have formal training and required education to have the right skills for undertaking research and other science and technology activities. They also need to have soft skills like leadership and management (McNie et al., 2016). Based on the skills, the human capital can be classified as researcher, crossover collaboration, inventor, and entrepreneur (Tijssen, 2018). For those organisations towards the market side, it is relevant to have dedicated personnel with industrial experience and technical knowledge to recognise the industrial pressures and priorities that could not be obvious to people whose experience is limited in the academic field (Arnold et al., 1998).

Moreover, some TAs do not have dedicated personnel, such as universitybased TA, consisting of academic and research staff. Zaichenko (2018), in his article, describe the academic and non-academic research workers in a TA. Some 
university-based organisations dedicate only a part of their time to the research activities because they have to carry out other academic activities such as teaching, tutoring, etc.

The infrastructure for a TA is essential for its performance. Many TAs do not have the equipment for specific activities, and then they are dependent on other organisations. Moreover, the funding scheme change is an issue for scaling up and upgrading the organisation facility. For example, the UK government set up programmes to contribute to infrastructures investment and establish extensive research facilities to address this issue. Moreover, some types of TAs provide access to the industries to use their scientific capabilities and expertise (Hoppmann, 2021). This aspect is crucial because it may be another form of income for the organisations as firms are often willing to pay for access and, if the TAs is campus-based, this makes firms closer to the university (BIS, 2015).

\section{Collaboration}

The Industry-university relationship has been widely studied in the past and is one of the priorities for innovation development and a priority for policymakers because it is considered one element of the technology strategy (Bayona Sáez et al., 2002; Meissner, 2019). Recently, additional programmes and initiatives in R\&D have been launched to strengthen university and industry collaboration (Meissner, 2019). Through this collaboration, both parties obtain advantages. For instance, firms with a strong capability can access trained personnel (students, professors) and facilities with leading-edge technologies. By doing so, firms can engage in open innovation activities (Fernández-Zubieta et al., 2016) and achieve revolutionary technology development. Besides, establishing a collaboration with the university over the years allows the academics to have a deep understanding of the industry's needs and identify new research opportunities to support the business (Dowling, 2015). At the same time, the universities collaborate with the industries to be exposed to practical problems. University and industry collaborate employing different mechanisms such as research support, cooperative project, knowledge transfer, and technology transfer (Bonaccorsi \& Piccaluga, 1994; Hagedoorn et al., 2000; Carayol, 2003). However, this collaboration seems to involve only the university and industry. However, the translational asset is an important "public-private research actor" (FernándezZubieta et al., 2016) and interacts with the university and industry encompassing the same means. Cooperation with the private sector allows this actor to undertake more applies research.

It is possible to enhance this aspect of the collaboration by analysing two variables: its proximity to the market and Its collaboration with the SMEs. Understanding how far the TAs are from the market helps to perceive the university's level integration. These organisations can be characterised by no direct association with HEIs or strong institutional ties with the university (Zaichenko, 2018). Therefore, this variable aims to identify the legal status embedded by such organisation (BIS, 2015). 
Considering the other dimension of the collaboration, TAs are involved in collaboration with businesses of every size but supporting SMEs' innovation process is essential for many countries, as they often lack knowledge and resources (Garengo, 2019). TAs often show interest in supporting the SMEs to encourage them to absorb new and external knowledge to accelerate innovation and then raise the knowledge transfer from TA to industry (Hoppmann, 2021). However, working with SMEs is costly and require specific competencies; then, these industries can be supported technologically by TAs with more commercial.

\section{Types of Translational Assets}

Based on the description of the factors used to describe the TAs from a review of literature is possible to map the different nature of these organisations. It is essential to remind the reader that this analysis focuses only on the translational asset that carries out translational research as a primary activity. Those organisations are based between the 3-6 TRL levels and are critical to support the innovation.

Following are highlighted the features for the typologies of translational assets considering the factors in Table 3 and some general details that shape the TAs. The authors acknowledged the lack of standard terminology for these organisations, the absence of a precise organisational mapping, and trying to account for the classification of the "mixed" translational assets. For such reason, we labelled the translational assets based on the characteristics that could identify them rather than using the standard terms in the literature (e.g. PRI, UIRC, R\&D). Such R\&D organisations have been labelled as exploratory organisation, plug organisation, and development organisation (Fig. 3).

Figure 3 shows three coloured circles, which identify how the ideal TAs are distributed along the critical factors' developmental continuum versus the innovation process. These organisations are labelled as exploratory, plug, and development. The graph below describes the different innovation processes on the vertical axis, which vary from basic research to manufacturing and sales. For instance, the TAs who embrace a university logic carry out processes toward the fundamental research and vice versa if they have a more commercial philosophy. In contrast, the horizontal axis identifies all the variables considered by the investigators to classify the TAs.

To classify the ideal typology of TAs, the variables on the horizontal axis have to fall on the same side of the spectrum. However, we are aware that not "one size fits all," and then there are trade-offs for each type of organisation because there could be a few cases of TA that could not match entirely the descriptions that we proposed and then fall outside the circle boundary. For instance, a university TA could be an independent entity within the university. It could better fit a different typology like, for example, the centre of excellence and cooperative research (see the red intersection between exploratory and plug organisation). 


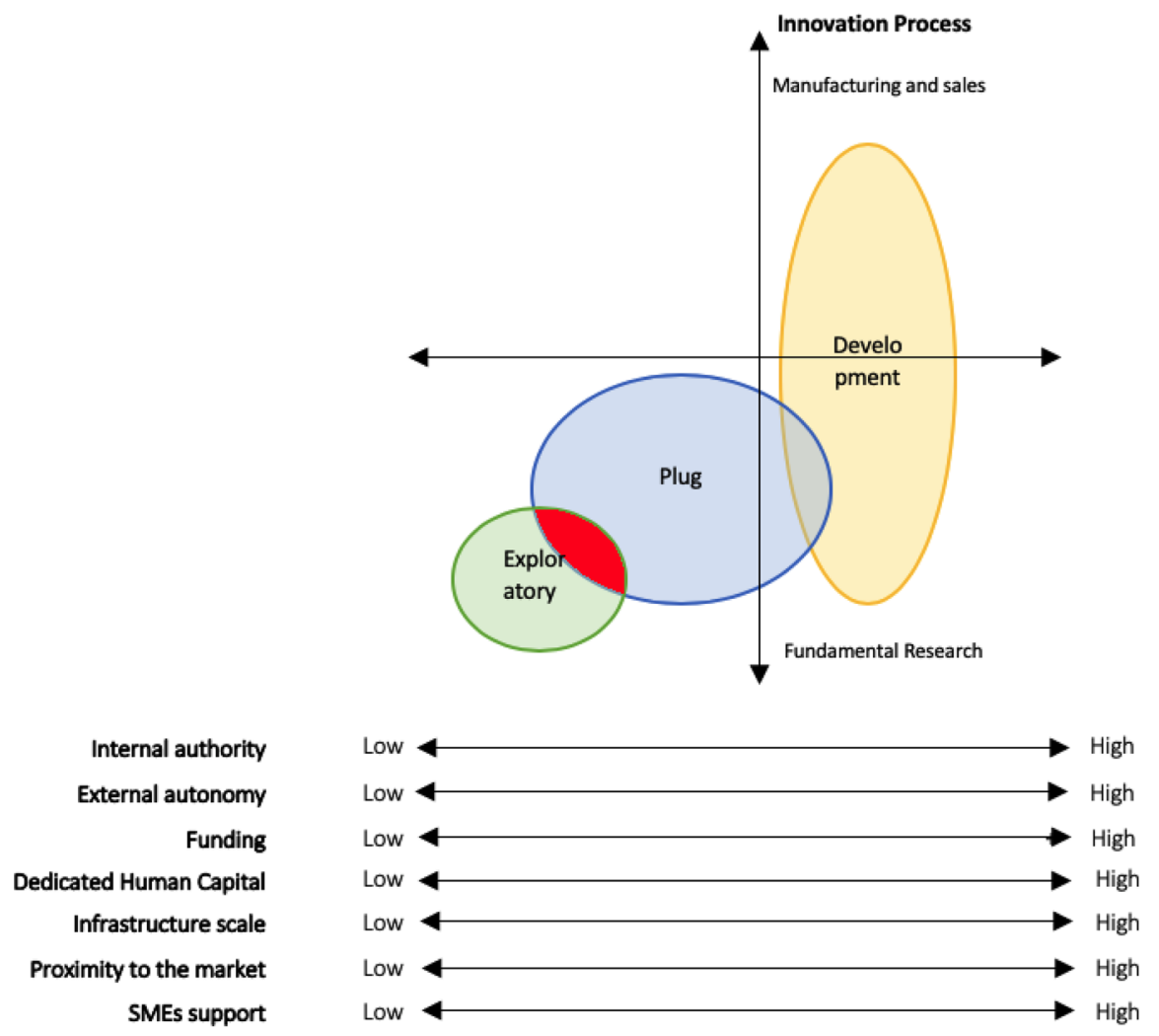

Fig. 3 Classification of the translational assets (own representation)

\section{Exploratory Asset}

This type of TA is typically university-based but can also be an off-campus facility owned by the university. It is usually supported and commonly owned by the university's department. Therefore, inside these organisations prevail the university logic, although they could run projects working closely with the end-users. However, the exploration organisations (EA) can vary their autonomy based on the added value brought to the university. Some cases of this typology can be associated with organisations as Max-Plank (Germany), CSIC (Spain), and CNR (Italy).

The name EA comes from their primary research focus that is the use-inspired basic research (a type of research that lies in between purely basic and purely applied research). Therefore, they ideate new solutions through new or existing knowledge, focusing on social and economic good. They also carry out other activities as teaching/education functions, tutoring to MSc and $\mathrm{PhD}$ students, and the technology transfer. 
The main features identified for the explorer organisation are as follows:

- They are sustained from stable government block funding (institutional funds and/or from basic/applied research programs) and individual grants. They perceive a small proportion from collaboration with the industries.

- Hierarchical structure with a variable degree of authority by the director(s) that report(s) to the Head of the Department, Dean, Chair, or Vice President. Explore director (initially) does have little management experience.

- EA is typically monitored by traditional academic line management and have formal hierarchy decision-making but weak;

- In the case of a strong relationship with industry, explorer organisations have an industrial advisory board or an industrial program;

- Researchers' autonomy can vary because they have to ask the directors to follow their research agenda due to the possible constraints of lack of equipment, R\&D expenses, and the type of research funding. Their autonomy increases in case they obtain personal external funding.

- EA has academic and research trained staff from various disciplines that focus their research on areas relevant to the industry. Some staff members dedicate only limited hours to the research activities because of their conflict role as they have to support other educational activities.

- The majority of these R\&D organisations have a low scale facility (e.g. laboratories or workshop) exiting within the university, but they might have a large-scale facility off the campus.

- Their proximity to the market is very far as they are a part of the university structure framework.

- The industries engage with this TA to establish a relationship with professors to have the opportunity to absorb new knowledge and have access to highly qualified students and public funds.

\section{Plug Asset}

Plug assets (PAs) are so called because they have been set up with the specific goal to satisfy the industry needs in a particular sector or technology. Their research activities are mission-oriented with a societal or technological target, yet they could carry out some research in the TRL 2-3 with the university support. Mainly, in these organisations, the phase of development prevails on the research one. PAs have the university and the industry logic involved, and this logic depends on the relation that the $R \& D$ organisation has with the university. Although most of the funding comes from the government, this does not affect the organisation's management. Some examples of these organisations are CSIRO (Australia) and Netherland Cancer Institute (Netherland). 
The main features identified for the explorer organisation are the following:

- The majority of the financial sources is public, and only a small percentage from private investments through short/ medium applied research contracts and consultancy. However, the "arms lengths" from the government could evolve over the years, bringing a gradual reduction of their core funding.

- TA with either own space like offices and laboratories or a university/other institution host them. In case they are hosted, they use the administration function of their host.

- The staff involved in the research activities hold mainly technical and scientific skills with different backgrounds.

- Usually, someone with industrial experience leads the organisation.

- This TA is set according to a top-down strategy under the ministerial control, but they never used a high level of authority on the management of the organisation.

- The decision-making process in some organisations could be influenced by external players such as advisory board made up of government and private firms as well as the stakeholder members.

- The individuals, led by a group leader or principal investigator (PI), have an intermediate level of autonomy due to the right level of decentralisation control.

- A good relationship with the university is established, and this limits the TA's operational flexibility because of its market logic.

- Firms engage with plug organisations to be assisted by accessing their knowhow and expertise and can help create a research network helping to find the right collaborators for the projects.

\section{Development Asset}

The development organisation (DA) aims to carry out applied R\&D and technology services with and for the industry to improve its competitiveness. However, they also carry out public support activity, and they are supported by around $30-50 \%$ from the government. These industry-oriented organisations can cover a wide TRL area, from 2 to 8 (e.g. Fraunhofer Society), because they do not provide only innovation service to the industry. They also offer service not necessarily commercial. They include this wide range of TRL activities because it depends on their research objective and their relationship with the university. These R\&D organisations have outstanding interaction with the university. They can have public, semi-public, and private non-for-profit governance. A few examples of DAs are the Fraunhofer Society (Germany), TNO (Netherland), Catapult (UK), and VTT (Finland).

The main features identified for the development organisation are as follows:

- Target to achieve the one-third model funding like Fraunhofer institutes: onethird core funding, one-third competitive funding, and one-third private financ- 
ing. This flexible funding scheme varies based on the organisation's research objective and how much the TA aims to be financially self-sustainable over the years.

- The organisational structure is hierarchical, but this is not a driver for a bureaucratic type. It comprises independent management established by the director(s) with an academic and industrial background with previous management experience.

- In this type of organisations, the research staff have a reasonable degree of autonomy.

- DAs have capabilities that consist of the expertise of people and the equipment that they own. They have extensive facilities with workshops and laboratories with leading-edge technology.

- Human capital plays a crucial role in these organisations. There are experts from academia and industry with a broader focus (scientific and management skills) and mostly held a PhD. They work alongside $\mathrm{PhD}$ and $\mathrm{MSc}$ student. Moreover, a part of the staff has also management expertise. In some cases, these organisations share human capital with universities.

- DAs are very close to the market, and to some extent, they have a close interaction with the university. They keep a high level of flexibility and operational autonomy to adapt to changing need of their customers and market.

- Mainly they support SMEs as they lack innovation capabilities through technology transfer, training, consultancy, and different R\&D services.

Figure 4 illustrates the key differences between the three types of TA. The figure is illustrative, not quantitative. It uses a scale, from low to high, to represent the characteristic reported in the description of the TAs. Thus, through the shift from "low" to "high," we want to show how the factors impact the TAs.

Fig. 4 Comparative typologies of TAs (own representation)

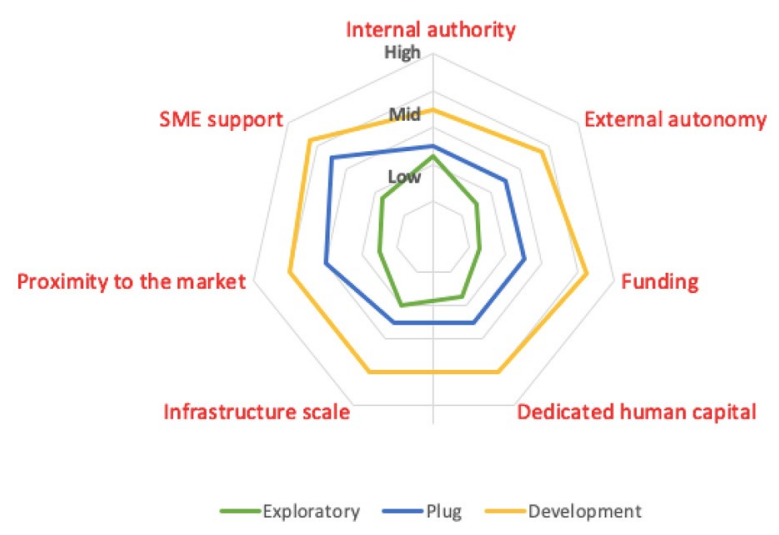




\section{Conclusion and Implications}

The past academic research in this area has focused on what TAs do and classifying them through a discrete representation employing a specific factor. We argued that before understanding the activities that these R\&D organisations develop, more attention is needed for the boundaries of such organisations considering multiple factors and illustrating them along a continuum.

This article fills this knowledge gap by outlining the TA in the literature's previous classification and addressing the investigators' research question. We suggested that the proposed classification of the translational assets aims to address this question by identifying three ideal types of TA through a bi-directional and multi-dimensional continuum. The three TA ideal types are labelled as exploratory, plug, and development. Also, this investigation offers novel theoretical insights and practical implications regarding a preliminary assessment of the existing dominant $\mathrm{R} \& \mathrm{D}$ organisations classifications. However, such an analysis is a heuristic approach to an initial step in a broad research project on understanding the establishment of translational assets. Moreover, such a study provides a theoretical and practical contribution.

\section{Theoretical Implication}

This study provides an initial cognitive contribution of the translational assets that are still poorly studied but very relevant for the industry innovation and policy for the local innovation systems.

The paper enriches the body of literature on the translational asset by fostering a deep understanding of the heterogeneity of the TAs and discussing the main characteristics. However, the literature in this field is still fragmented. The authors pulled together perspectives from previous studies to classify the TAs and propose a new classification by improving the relevant dimensions to describe each type of translational infrastructure's boundaries. Previous investigations are characterised by their quantitative nature and the limited number of factors. Besides, this study contributes to the past research limitations through the factors' representation and considering a more comprehensive range of factors. The characteristics that we selected for the classification are shown on a continuum rather than discrete value. Such factors allowed us to identify three ideal groups of translational assets: exploratory, plug and development.

The ex-ante classifications were limited only to a discrete categorisation of organisations. The discrete classifications could be inadequate because they have brought to the exclusion or misclassification of all those with a hybrid nature. The authors fixed this downside by improving the selection of relevant factors to build a new classification for the ideal type of TAs. 


\section{Practical Implication}

Although this article is a review of the literature, it has a practical contribution. The proposed classification provides a better understanding for managers of the organisational heterogeneity of the TAs, implying an accurate description of the boundaries that shape these bodies. Thus, even if it is an early stage, such typology gives insights to facilitate the practitioners to design new assets within a particular context. On the other hand, it can be used repeatedly to observe the changes of the different characteristics that influence the overall alignment of the organisational environment. Therefore, the classification can be used as a tool to support the TAs design.

\section{Research Limitations and Further Research}

Considering this evidence, the authors attempted to shed light on the topic and contribute to the translational infrastructures' literature. However, as with every research, this analysis presents some limitations that could be as input for future research. The first limitation and that more obvious is the lack of substantial literature inherent to the topic. The literature is significantly fragmented due to the lack of clear understanding because of the complex and challenging concepts. Moreover, most of the sources are not up to date, and this, in some way, could impact the research and its flexibility. The second limitation is that the classification may need a trade-off to embed all the type or TAs and refine the description of these ideal types.

However, the context of TAs is vast, and our results suggest some direction for future research. For instance, further studies could address other configurations of TA and consider different factors. With our initial study, we provide an outline of the TA, and then it would be interesting to see in future research the application of the framework to classify TA in a specific sector, within a particular country or benchmark different national innovation systems. There are differences across the various countries in terms of management systems, funding schemes, actors, and different administrations. All these factors are contingent on policies, funding structure, sector, management, and stakeholders. Thus, we need to know more about how these factors may influence the TAs to have a more unified understanding of these organisations. This suggests another way to grow our knowledge in the TA field by investigating additional factors or extend the work carrying on empirical analysis.

Open Access This article is licensed under a Creative Commons Attribution 4.0 International License, which permits use, sharing, adaptation, distribution and reproduction in any medium or format, as long as you give appropriate credit to the original author(s) and the source, provide a link to the Creative Commons licence, and indicate if changes were made. The images or other third party material in this article are included in the article's Creative Commons licence, unless indicated otherwise in a credit line to the material. If material is not included in the article's Creative Commons licence and your intended use is not permitted by statutory regulation or exceeds the permitted use, you will need to obtain permission directly from the copyright holder. To view a copy of this licence, visit http://creativecommons.org/ licenses/by/4.0/. 


\section{References}

Adams, J. D., Chiang, E. P., \& Starkey, K. (2001). Industry-university cooperative research centre. Journal of Technology Transfer, 26(1), 73-86.

AIRTO. (2018). A taxonomy of the UK's Innovation, Research \& Technology sector.

Aldrich, H., \& Herker, D. (1977). Boundary spanning roles and organization structure. The Academy of Management Review, 2(1), 217-230.

Arnold, E., Barker, K., \& Slipersæter, S. (2010). Research Institutes in the ERA.

Arnold, E., Knee, P., Carlberg, M., Giarracca, F., \& Javorka, Z. (2012). Research centres in Ireland: Funding models, oversight mechanisms and vision of a future research centre landscape. Dublin. Technopolis Group.

Arnold, E., Rush, H., Bessant, J., \& Hobday, M. (1998). Strategic planning in research and technology institutes. $R \& D$ Management, 28(2), 89-100.

Arrigo, E. (2018). Open innovation and market orientation: An analysis of the relationship. Journal of Economy, 9(1), 150-161.

Auerswald, P. E., \& Branscomb, L. M. (2003). Valleys of death and Darwinian seas: Financing the invention and innovation transition in the United States. Journal of Technology Transfer, 28(1), 227-239.

Balthasar, A., Battig, C., \& Wilhelm, B. (2000). Developers: Key actors of the innovation process. Types of developers and their contacts to institutions involved in research and development, continuing education and training and the transfer of technology. Technovation, 20(10), pp. 523-538.

Bayona Sáez, C., Garcí Marco, T. N. A., \& d Huerta Arribas, E. (2002). Collaboration in R\&D with universities and research centres: An empirical study of Spanish firms. R\&D Management, 32(4), 321-341.

Bazan, C. (2019). "From lab bench to store shelves": A translational research \& development framework for linking university science and engineering research to commercial outcomes. Journal of Engineering and Technology Management, 53(1), 1-18.

Betz, F., Carayannis, E., Jetter, A., Min, W., Phillip, F., \& Woo Shin, D. (2016). Modelling an innovation intermediary system within a helix. Journal of Knowledge Economy, 7(1), 587-599.

Boardman, C., \& Denis, G. (2010). The new science and engineering management: Cooperative research centre as government policies, industry strategies, and organizations. Journal Technology Transfer, $35(1), 445-459$.

Boardman, C. (2012). Organisational capital in boundary-spanning collaboration: Internal and external approaches to organisational structure and personnel authority. Journal of Public Administration Research and Theory, 92(1), 497-526.

Boardman, C., \& Corley, E. (2008). University research centre and the composition of research collaboration. Research Policy, 37(1), 900-913.

Bonaccorsi, A., \& Piccalunga, A. (1994). A theoretical framework for the evolution of the universityindustry relationship. $R \& D$ Management, 24(3), 229-247.

Bozeman, B., \& Crow, M. (1990). The environments of U.S. R\&D laboratories: political and market influences. Policy Science, 23(1), 25-56.

Bozeman, B., \& Boardman, P. C. (2003). Managing the new multipurpose, multidiscipline university research center: Institutional innovation in the academic community. IBM Endowment for the Business of Government.

Bozeman, B., \& Moulton, S. (2011). Integrative publicness: A framework for public management strategy and performance. Journal of Public Administration Research and Theory, 21(3), i363-i380.

Burns, T., \& Stalker, G. M. (1961). The management of innovation. London: Tavistock Publications.

Carayol, N. (2003). Objectives, agreements and matching in science-industry collaborations: reassembling the pieces of the puzzle. Research Policy, 32(6), 887-908.

Carper, W. B., \& Snizek, W. E. (1980). The nature and types of organizational taxonomies: An overview. Academy of Management, 5(1), 65-75.

Charles, D., \& Ciampi Stancova, K. (2014). Research and technology organisations and smart specialisation. S3 Policy Brief Series, No. 15/2015. European Commission, Joint Research Centre, Institute for Prospective Technological Studies, Spain.

Chesbrough, H., Vanhaverbeke, W., \& West, J. (2006). Open Innovation: Researching a new paradigm. Oxford University Press.

Chompalov, I., Genuth, J., \& Shrum, W. (2002). The organization of scientific collaborations. Research Policy, 31(1), 749-767. 
Ciappetti, L., \& Perulli, P. (2018). New tech spaces for old tech places? Exploring the network of research and technology organizations across North Italian Regions. European Planning Studies, 26(1), 192-211.

Cohen, W. M., \& Levinthal, D. A. (1989). Innovation and learning: The two faced of R\&D. The Economic Journal, 99(397), 569-596.

Collier, D., Laporte, J., \& Seawright, D. (2008). Typologies: Forming concepts and creating categorical variables. In: J. M. Box-Steffensmeier, H. E. Brady and D. Collier, The Oxford handbook of political methodology, 1st ed. Oxford: Oxford University Press, pp. 152-173.

Corley, E., Boardman, P., \& Bozeman, B. (2006). Design and the management of multi-institutional research collaboration: Theoretical implications from two case studies. Research Policy, 35(1), 975-993.

Crow, M., \& Bozeman, B. (1987a). R\&D laboratory classification and public policy: The effects of environmental context on laboratory behaviour. Research Policy, 16(5), pp. 229-258.

Crow, M., \& Bozeman, B. (1987b). A new typology for R\&D laboratories: Implications for policy analysts. Journal of Policy Analysis and Management, 6(3), pp. 328-341.

Cruz-Castro, L., \& Sanz-Menéndez, L. (2018). Autonomy and authority in public research organisations: Structure and funding factors. Minerva, 56(1), 135-160.

Cruz-Castro, L., Bleda, M., Derrick, G. E., Jonkers, K., Martinez. C., \& Sanz-Menendez, L. (2011). Public sector research funding.

Cruz-Castro, L., Jonkers, K., \& Sanz-Menéndez, L. (2015). The internationalisation of research institutes. In L. Wedlin \& M. Nedeva (Eds.), Towards European science: Dynamics and policy of an evolving European research space (pp. 175-198). Edward Elgar Publishing.

Cruz-Castro, L., Sanz-Menéndez, L., \& Martinez, C. (2012). Research centre in transition: Patterns of convergence and diversity. Journal of Technology Transfer, 37(1), 18-42.

Cruz-Castro, L., Martínez, C., Peñasco, C., \& Sanz-Menéndez, L. (2020). The classification of public research organisations: Taxonomical explorations. Research Evaluation, pp. 1-15.

D'Este, P., \& Patel, P. (2007). University-industry linkages in the UK: What are the factors underlying the variety of interactions with industry? Research Policy, 36(1), 1295-1313.

D'Este, P., \& Perkmann, M. (2011). Why do academics engage with industry? The entrepreneurial university and individual motivations. Journal of Technology Transfer, 36(1), 316-339.

De Waele, L., Berghman, L., \& Matthyssens, P. (2015). Defining hybridity and hybridity contingencies in public organisations: An alternative conceptual model. Contingency, Behavioural and Evolutionary Perspectives on Public and Non-Profit Governance Studies in Public and Non-Profit Governance, $4(1), 113-154$.

Department of Business, Innovation \& Skills (BIS). (2015). Research and innovation organisations in the UK: Innovation functions and policy issues.

Dowling, D. A. (2015). The Dowling review of business-university research collaborations.

EARTO. (2014). The TRL scale as a research \& innovation policy tool, EARTO Recommendations.

Etzkowitz, H., \& Kemelgor, C. (1998). The role of research centres in the collectivisation of academic science. Minerva, 36(1), 271-288.

Etzkowitz, H., \& Leydesdorff, L. (2000). The dynamics of innovation: From national system and "Mode 2" to a triple helix of university-industry-government relations. Research Policy, 29(1), 109-123.

Etzkowitz, H., Germain-Alamartine, E., Keel, J., Kumar, C., Smith, C. N., \& Albats, E. (2019). Entrepreneurial university dynamics: Structured ambivalence, relative deprivation and institution-formation in the Stanford innovation system. Technology Forecasting \& Social Change, 141(1), 159-171.

Feller, I., Ailes, C. P., \& Roessner, J. D. (2002). Impacts of research universities on technological innovation in industry: evidence from engineering research centers. Research policy, 31(3), 457-474.

Fernández-Zubieta, A., Andújar-Nagore, I., Giachi, S., \& Fernández-Esquinas, M. (2016). New organisational arrangements for public-private research collaboration. Journal of Knowledge Economy, 7(1), $80-103$.

Garegano, P. (2019). How bridging organisations manage technology transfer in SMEs: An empirical investigation. Technology Analysis \& Strategic Management, 31(4), 477-491.

Geiger, R. L. (1990). Organized research units-The role in the development of university research. The Journal of Higher Education, 61(1), 1-19.

Gray, D. O. (2000). Government-sponsored industry-university cooperative research: An analysis of cooperative research center evaluation approaches. Research Evaluation, 8(1), 57-67.

Gray, D. O., Lindblad, M., \& Rudolph, J. (2001). Industry-university research centers: A multivariate analysis of member retention. Journal of Technology Transfer, 26(1), 247-254. 
Gray, D., Boardman, C., \& Rivers, D. (2013). The new science and engineering management: Cooperative research centers as intermediary organisations for government policies and industry strategies. In D. Gray, C. Boardman, \& D. Rivers (Eds.), Cooperative research centers and technical innovation: Government policies, industry strategies, and organizational dynamics (1st ed., pp. 3-33). Springer.

Gray, D., Johnson, E., \& Gidley, T. R. (1986). Industry-university projects and centers. An empirical comparison of two federally funded models of cooperative science. Evaluation Review, 10(6), pp. 776-793.

Gulbrandsen, M. (2011). Research institutes as hybrid organisations: Central challenges to their legitimacy. Policy Science, 44(3), 215-230.

Gustafsson, K. M., \& Lidskog, R. (2018). Boundary organizations and environmental governance: Performance, institutional design, and conceptual development. Climate Risk Management., 19, 1-11.

Haeussler, C., \& Assmus, A. (2021). Bridging the gap between invention and innovation: Increasing success rates in publicly and industry-funded clinical trials. Research Policy, 50(2), 1-17.

Hagedoorn, J., Link, A. N., \& Vonortas, N. S. (2000). Research partnership. Research Policy, 129(1), $567-586$.

Hambrick, D. C. (1983). An empirical typology of mature industrial-product environment. Academy of Management Journal, 26(1), 213-230.

Hameri, A. (1996). Technology transfer between basic research and industry. Technovation, 16(2), 51-57.

Hauser, H. (2010). The current and future role of technology innovation centres in the UK. Department for Business, Innovation and Skills (BIS).

Hoppmann, J. (2021). Hand in hand to Nowhereland? How the resource dependence of research institutes influences their co-evolution with industry. Research Policy. 50(2), pp. 104145

House Of Common. (2011). Technology and innovation centre. Second report of Session 2010-11. London: The Stationary Office Limited.

Ikenberry, S. O., \& Friedman, R. C. (1972). Beyond academic departments: The story of institutes and centre. Jossey-Bass Inc.

Jordan, G. B. (2006). Factors influencing advances in basic and applied research: variation due to diversity in research profiles. In: J. Hage and M. T. H. Meeus, Innovation, science, and institutional change, eds. Oxford, UK: Oxford University Press, pp. 173-195.

Jucevicius, G., Juceviciene, R., Gaidelys, V., \& Kalman, A. (2016). The emerging innovation ecosystem and "valley of death": Towards the combination of entrepreneurial and institutional approaches. Inžinerine Ekonomika- Engineering economics.

Kilmann, R. H. (1983). A typology of organizations typologies: Toward parsimony and integration in the organizational sciences. Human Relations, 36(6), 523-548.

Lal, B., Boardman, P. C., Deshmukh-Towery, N., \& Link, J. (2007). Designing the future generation of NSF engineering research centers: Insights from worldwide practice. Science and Technology Policy Institute.

Leydesdorff, L., \& Etzkowitz, H. (1995). The triple helix as a model for innovation studies. Science and Public Policy, 25(3), 195-203.

McKelvey, B. (1982). Organisational systematics-taxonomy, evolution, classification. University of California Press, Ltd.

McNie, E., Parris, A., \& Sarewitz, D. (2016). Improving the public value of science: A typology to inform discussion, design and implementation of research. Research Policy, 45(4), 884-895.

Meissner, D. (2019). Public-private partnership models for science, technology, and innovation cooperation. Journal of Knowledge Economy., 10(4), 1341-1361.

Morrison, A., \& Pattinson, M. (2020). University-industry collaboration. Lille: Interreg Europe Policy Learning Platform.

Muizniece, L. (2020). University autonomy and commercialization of publicly funded research: The case of Latvia. Journal of the Knowledge Economy, pp. 1-23.

OECD. (2011a). Public research institutions: Mapping sector trends. OECD Publishing.

OECD. (2011b). Actor brief public research organisations (PRO).

OECD. (2019). University-Industry collaboration-New evidence and policy options.

O'Kane, C., Mangematin, V., Zhang, J. A., \& Cunningham, J. A. (2020). How university-based principal investigators shape a hybrid role identity. Technological Forecasting \& Social Science, 159(C), pp. $1-11$.

Philbin, S. (2011). An investigation of the development and management of university research institutes. Journal of Research Administration, 43(1), 103-122. 
Pugh, D. S. (Ed.). (1990). Organization Theory: Selected Readings. Harmondsworth: Penguin.

Rich, P. (1992). The organizational taxonomy: Definition and design. The Academy of Management Review, 17(4), 758-781.

Sarpong, D., AbdRazak, A., Alexander, E., \& Meissner, D. (2017). Organizing practices of university, industry and government that facilitate (or impede) the transition to a hybrid triple helix model of innovation. Technological Forecasting \& Social Change, 123, 142-152.

Sanz-Menéndez, L., \& Cruz-Castro, L. (2003). Coping with environmental pressures: Public research organisations responses to funding crises. Research Policy, 32(8), 1293-1308.

Sanz-Menéndez, L., Cruz-Castro, L., Jonkers, K., Derrick, G. E., Bleda, M., \& Martínez, C. (2011). Public research organisations. OECD, The Innovation Policy Platform Policy Briefs.

Subtil de Oliveira, L., Soares Echeveste, M., Nogueira Cortimiglia, M., \& Gularte, A. C. (2019). Open Innovation in Regional Innovation Systems: Assessment of Critical Success Factors for Implementation in SMEs. Journal of the Knowledge Economy. 10(1), pp. 1597-1619.

Stahler, G. J., \& Tash, W. R. (1994). Centers and institutes in the research university: Issues, problems, and prospects. Journal of Higher Education, 65(5), 540-554.

Tijssen, R. J. W. (2018). Anatomy of use-inspired researchers: From Pasteur's Quadrant to Pasteur's T Cube model. Research Policy., 47(9), 1626-1638.

Youtie, J., Libaers, D., \& Bozeman, B. (2006). Institutionalization of university research centers: The case of the National Cooperative Program in Infertility Research. Technovation, 26(9), 1055-1063.

Zaichenko, S. (2018). The human resource dimension of science-based technology transfer: Lessons from Russian RTOs and innovative enterprises. Journal of Technology Transfer, 43(2-3), 368-388.

Publisher's Note Springer Nature remains neutral with regard to jurisdictional claims in published maps and institutional affiliations. 